\title{
The Electrochemical Performances of Zn-Al-Hydrotalcites in Zn-Ni Secondary Batteries
}

\author{
Xiaohua $Y u^{l}$, Yasong $Q u^{1}$,Shuanglin $Y^{1}{ }^{1}$,Yunting Cai $^{1}$, Xiaocai He ${ }^{2}$, Pan Feng ${ }^{1}$, \\ Ying Wang ${ }^{1}$ Gang Xie $e^{1,3}$ \\ ${ }^{1}$ Faculty of metallurgy and energy engineering, Kunming University of Science and Technology, \\ Kunming Yunnan 650093, China \\ ${ }^{2}$ Yunnan Metallurgical Group Chuang Neng Metal fuel battery Co., LTD, Kunming 650503, China \\ ${ }^{3}$ State key laboratory of pressure hydrometallurgical technology of associated non-ferrous metal \\ resources, Kunming Yunnan 650503, China \\ *E-mail: yxhyxh1978@aliyun.com
}

doi: $10.20964 / 2019.01 .34$

Received: 14 September 2018 / Accepted: 5 November 2018 / Published: 30 November 2018

\begin{abstract}
Zn-Al-hydrotalcites (Zn-Al-LDHs) are successfully synthesized by a hydrothermal method and a coprecipitation method and are investigated as negative electrode materials for $\mathrm{Zn}-\mathrm{Ni}$ batteries. Scanning electron microscope (SEM) images, X-ray diffraction (XRD) patterns and laser scattering particle analysis show that the as-prepared sample is flaky in structure and well-crystallized, and the particle sizes are approximately 20-40 $\mu \mathrm{m}$. The electrochemical performances of Zn-Al-LDHs determined by different methods are investigated by potentiodynamic polarization, electrochemical impedance spectroscopy (EIS) and galvanostatic charge/discharge measurements. Compared with pure $\mathrm{ZnO}$ powders, Zn-Al-LDHs have good anticorrosion ability. The lower charge platform (1.86 V) and higher discharge platform $(1.71 \mathrm{~V})$ of $\mathrm{Zn}$-Al-LDHs indicate that they have better charge/discharge performance as negative active materials for $\mathrm{Zn}-\mathrm{Ni}$ batteries. These findings show excellent cycle stability in the 40th cycle, with the capacity retention ratio of $81.4 \%$ and cycle effciency of approximately $90 \%$, which are much higher than those of pure $\mathrm{ZnO}(44 \%)$.
\end{abstract}

Keywords: Zn-Al-LDHs; Zn-Ni secondary batteries; Electrode performance; Cyclic stability

\section{FULL TEXT}

(C) 2019 The Authors. Published by ESG (www.electrochemsci.org). This article is an open access article distributed under the terms and conditions of the Creative Commons Attribution license (http://creativecommons.org/licenses/by/4.0/). 